\title{
Micro Salting-Out Assisted Matrix Solid-Phase Dispersion: A Simple and Fast Sample Preparation Method for the Analysis of Bisphenol Contaminants in Bee Pollen
}

\author{
Jianing Zhang ${ }^{1}$, Fengjie Yu ${ }^{1}$, Yunmin Tao ${ }^{1}$, Chunping Du ${ }^{2,3}$, Wenchao Yang ${ }^{1,2,3} \mathbb{C}$, Wenbin Chen ${ }^{2,3, *(1)}$ \\ and Xijuan Tu ${ }^{2,3, *}$ \\ 1 College of Food Science, Fujian Agriculture and Forestry University, Fuzhou 350002, China; \\ zjnlo1225@163.com (J.Z.); yfj918@126.com (F.Y.); july766@126.com (Y.T.); beesyang@gmail.com (W.Y.) \\ 2 College of Bee Science, Fujian Agriculture and Forestry University, Fuzhou 350002, China; du_cp39@163.com \\ 3 College of Animal Sciences, Fujian Agriculture and Forestry University, Fuzhou 350002, China \\ * Correspondence: wbchen@fafu.edu.cn (W.C.); xjtu@fafu.edu.cn (X.T.)
}

check for updates

Citation: Zhang, J.; Yu, F.; Tao, Y.; Du, C.; Yang, W.; Chen, W.; Tu, X. Micro Salting-Out Assisted Matrix Solid-Phase Dispersion: A Simple and Fast Sample Preparation Method for the Analysis of Bisphenol Contaminants in Bee Pollen. Molecules 2021, 26, 2350. https:// doi.org/10.3390/molecules 26082350

Academic Editors: Victoria Samanidou and Irene Panderi

Received: 19 March 2021

Accepted: 16 April 2021

Published: 18 April 2021

Publisher's Note: MDPI stays neutral with regard to jurisdictional claims in published maps and institutional affiliations.

Copyright: (c) 2021 by the authors. Licensee MDPI, Basel, Switzerland. This article is an open access article distributed under the terms and conditions of the Creative Commons Attribution (CC BY) license (https:/ / creativecommons.org/licenses/by/ $4.0 /)$.

\begin{abstract}
In the present work, a novel sample preparation method, micro salting-out assisted matrix solid-phase dispersion ( $\mu$-SOA-MSPD), was developed for the determination of bisphenol A (BPA) and bisphenol B (BPB) contaminants in bee pollen. The proposed method was designed to combine two classical sample preparation methodologies, matrix solid-phase dispersion (MSPD) and homogenous liquid-liquid extraction (HLLE), to simplify and speed-up the preparation process. Parameters of $\mu$-SOA-MSPD were systematically investigated, and results indicated the significant effect of salt and $\mathrm{ACN}-\mathrm{H}_{2} \mathrm{O}$ extractant on the signal response of analytes. In addition, excellent clean-up ability in removing matrix components was observed when primary secondary amine (PSA) sorbent was introduced into the blending operation. The developed method was fully validated, and the limits of detection for BPA and BPB were $20 \mu \mathrm{g} / \mathrm{kg}$ and $30 \mu \mathrm{g} / \mathrm{kg}$, respectively. Average recoveries and precisions were ranged from $83.03 \%$ to $94.64 \%$ and $1.76 \%$ to $5.45 \%$, respectively. This is the first report on the analysis of bisphenol contaminants in bee pollen sample, and also on the combination of MSPD and HLLE. The present method might provide a new strategy for simple and fast sample preparation of solid and semi-solid samples.
\end{abstract}

Keywords: sample preparation; matrix solid-phase dispersion; salting-out; homogenous liquidliquid extraction; bisphenol; bee pollen

\section{Introduction}

In the past decade, matrix solid-phase dispersion (MSPD) has achieved great progress in the sample preparation of complex samples [1-4]. The major merit of MSPD is the accomplishing of extraction and clean-up procedures in one step especially for solid and semi-solid samples $[5,6]$. Due to its simplicity and flexibility, MSPD has been widely applied in the analysis of food, environmental, and biological matrices [3]. In recent years, modifications of the classical MSPD have been reported to refine the original method. In the ultrasonic-assisted MSPD, ultrasonication was performed on the MSPD column for speeding the process and improving the extraction yield [7,8]. Additionally, vortex and homogenization have been reported to replace the column elution and blending in the classical MSPD, respectively, to simplify the procedure of preparation [9-14]. Another method for the replacement of column was the magnetically assisted MSPD, in which magnetic ion liquid [15] or particles [16] were used as dispersants. Thus, analytes could be simply extracted by magnetic isolation. Additionally, micro/mini-MSPD, which reduced the sample amount in the protocol, was a good choice for reducing the consumption of sample and material [17-24] and improving the greenness of MSPD [25]. These improved methods have promoted the development of sample preparation technology for solid and semi-solid sample. 
Homogenous liquid-liquid extraction (HLLE) is an alternative method to the traditional liquid-liquid extraction. In HLLE, a mixture of water and water-miscible solvent is applied for the liquid extraction, which is triggered to form into two separate phases after the introduction of a phase separation agent or condition [26-29]. Acetonitrile (ACN)water-based protocol is in the hot area of HLLE studies, particularly the use of salt as a phase separation agent combined with dispersive solid-phase extraction (d-SPE), has been developed into the popular QuEChERS method [30,31]. Compared with traditional liquid-liquid extraction, HLLE shows the advantage of extraction over a wider polarity range. Furthermore, $\mathrm{ACN}$ is compatible with chromatography systems; this means that the obtained extract could be directly injected without additional operation of solvent exchange. These enable HLLE to be widely applied in the analysis of multiple analytes in complex matrices [26-28,31].

In the present work, we combined the principles of MSPD and HLLE to develop a novel sample preparation method named micro salting-out assisted MSPD ( $\mu$-SOA-MSPD). Impacts of its parameters were systematically investigated, and the proposed method was demonstrated to be simple, rapid, and effective with combining advantages of both MSPD and HLLE. Bisphenol compounds, a group of widespread environmental contaminants that can potentially pollute honeybee products [32,33], were successfully determined in bee pollen matrix by using the $\mu$-SOA-MSPD and HPLC-fluorescence detection. To the best of our knowledge, this is the first report of HLLE-modified MSPD, and also the first report on the analysis of bisphenols contaminant in bee pollen sample.

\section{Results and Discussion}

\subsection{Micro Salting-Out Assisted MSPD}

The schematic procedure of the proposed $\mu$-SOA-MSPD method is shown in Figure 1. Firstly, the sample is blended with salt and sorbent by way of the classical MSPD methodology. According to the principle of MSPD, this step is designed for the disruption of solid sample by using the shearing and grinding force in the blending operation [5]. Afterwards, the blended materials are transferred into a tube and vortexed with solution of $\mathrm{ACN}-\mathrm{H}_{2} \mathrm{O}$ mixture. Under vortexing, salt is dissolved into the extractant, triggering the phase separation of ACN from its aqueous solution. After short-time centrifugation to make the phase separation clear, analytes are partitioned into the upper $\mathrm{ACN}$ phase with high efficiency. Finally, aliquot of the ACN phase is collected and analyzed by HPLC system.

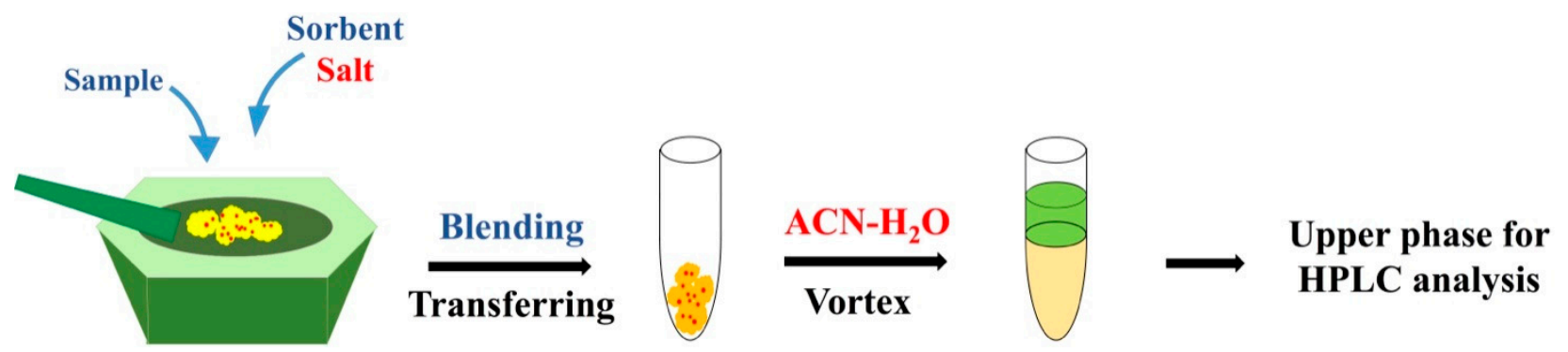

Figure 1. Schematic presentation of micro salting-out assisted matrix solid-phase dispersion ( $\mu$-SOA-MSPD).

The unique aspect of this $\mu$-SOA-MSPD method is the introduction of salting-out induced phase separation into the procedure, which makes the HLLE simultaneously accomplished in the MSPD process. As a result, analytes are directly partitioned into the upper ACN phase in this modified MSPD method, which enables the concentration of analytes and provides a substantial clean-up effect as the majority of the matrix is isolated into the lower $\mathrm{H}_{2} \mathrm{O}$ phase. Furthermore, the sorbent material used in the blending step could provide an additional clean-up effect similar to the dispersive solid-phase extraction (d-SPE) [30]. Based on these clean-up effects resulting from the phase partition and the d-SPE behavior of sorbent, the cartridge generally used in the classical MSPD is eliminated in the proposed method. This means that the column wash and elution, the most solvent- 
and time-consuming steps, are also omitted. Thus, the proposed method possesses the merit of a much simpler procedure, as well as less consumption of time, labor, and organic solvents. These would make the modified MSPD procedure greener than the classical one according to the idea of green analytical chemistry [34].

\subsection{Salting-Out Parameters}

Salt is designed as both the dispersant for the disruption of sample and the phase separation agent in the following partition performance. $\mathrm{MgSO}_{4}$ and $\mathrm{NaCl}$ were investigated, due to their high efficiency for the phase separation of $\mathrm{ACN}-\mathrm{H}_{2} \mathrm{O}$ mixture $[29,35]$. Application of $\mathrm{MgSO}_{4}$ in $\mathrm{ACN}-\mathrm{H}_{2} \mathrm{O}$-based HLLE has shown high extraction yields for compounds with a wide polarity range due to the large volume of separated ACN phase. As regards the $\mathrm{NaCl}$, it provides a relatively small volume of $\mathrm{ACN}$ phase, and thus a higher signal response for the target compounds. The effects of salts and $\mathrm{ACN}-\mathrm{H}_{2} \mathrm{O}$ mixture on the calculated recovery and the signal response of the analytes are compared in Figure 2.
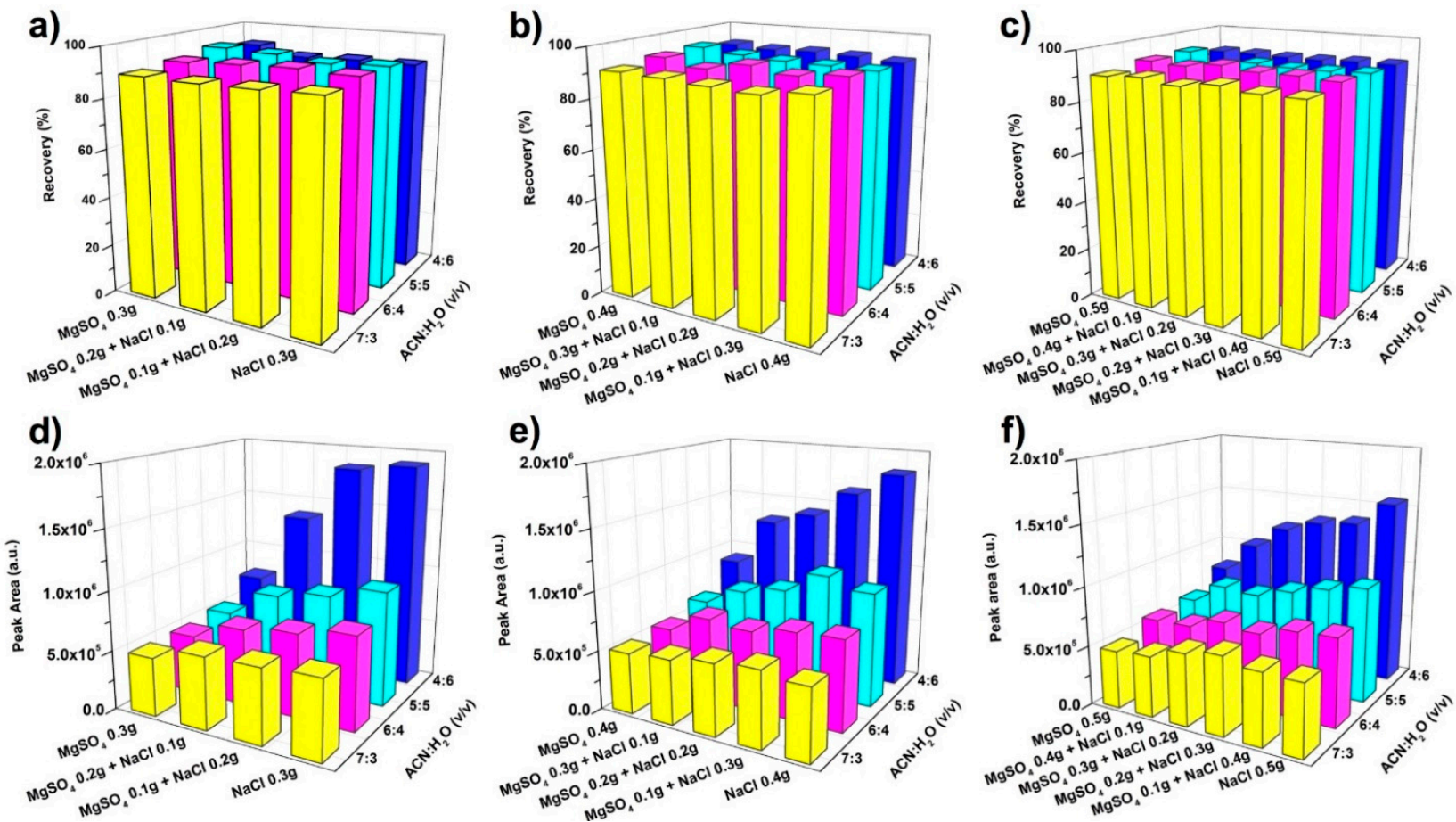

Figure 2. Effects of salts and $\mathrm{ACN}-\mathrm{H}_{2} \mathrm{O}$ mixture on the calculated recovery $(\mathbf{a}-\mathbf{c})$ and signal response $(\mathbf{d}-\mathbf{f})$ of bisphenol A (BPA). The total mass of salts were $0.3 \mathrm{~g}(\mathbf{a}, \mathbf{d}), 0.4 \mathrm{~g}(\mathbf{b}, \mathbf{e})$, and $0.5 \mathrm{~g}(\mathbf{c}, \mathbf{f})$. Mean values of triplicate experiments are presented.

High recovery values for both bisphenol A (BPA) and bisphenol B (BPB) were observed in extensive salting-out conditions. As shown in Figure $2 \mathrm{a}-\mathrm{C}$, the calculated recoveries of BPA were in the range between $88.08 \%$ and $93.89 \%$. Under the same recipe of salts, recovery of BPA was slightly increased as the concentration of $\mathrm{ACN}$ in the $\mathrm{ACN}-\mathrm{H}_{2} \mathrm{O}$ mixture increased from 4:6 to 7:3 (v/v). Meanwhile, with the same $\mathrm{ACN}-\mathrm{H}_{2} \mathrm{O}$ solution, the recipe of salts did not show significant effect on the recovery values of BPA. For instance, under the concentration of $4: 6(\mathrm{v} / \mathrm{v})$, as the recipe of salts changed from $0.5 \mathrm{~g}$ of $\mathrm{MgSO}_{4}$ to $0.5 \mathrm{~g}$ of $\mathrm{NaCl}$, recovery of BPA varied slightly from $90.43 \%$ to $90.71 \%$.

Different from the results on recovery, the signal response of bisphenols was significantly affected by the salts and the $\mathrm{ACN}-\mathrm{H}_{2} \mathrm{O}$ mixture (Figure $2 \mathrm{~d}-\mathrm{f}$ ). Under the same recipe of salts, the volume of upper phase decreased as the concentration of ACN in the ACN-H $\mathrm{H}_{2} \mathrm{O}$ mixture was reduced. As a result, concentration of analytes in the ACN phase could be significantly increased. For example, with the presence of $0.3 \mathrm{~g}$ of $\mathrm{NaCl}$, as the concentration of ACN was reduced from 7:3 to 4:6 (v/v), the signal response of BPA increased to about triple. On the other hand, since $\mathrm{NaCl}$ resulted into smaller volume of ACN phase 
than $\mathrm{MgSO}_{4}[35,36]$, signal response of BPA became much higher when the recipe of salts changed from total $\mathrm{MgSO}_{4}$ to $\mathrm{MgSO}_{4}-\mathrm{NaCl}$ mixture, and then to total $\mathrm{NaCl}$. Typically, in the ACN- $\mathrm{H}_{2} \mathrm{O}$ mixture of $4: 6(v / v)$, the signal response of BPA obtained by $0.3 \mathrm{~g}$ of $\mathrm{MgSO}_{4}$ was only about $40 \%$ of that using the same mass of $\mathrm{NaCl}$. It is important to notice that increasing the mass of salts also led to the increase of the volume of ACN phase, and in consequence reducing the signal. When the concentration of $\mathrm{ACN}$ was $4: 6(v / v)$, as the mass of $\mathrm{NaCl}$ increased from $0.3 \mathrm{~g}$ to $0.5 \mathrm{~g}$ (Figure $2 \mathrm{~d}-\mathrm{f}$ ), signal response of BPA decreased about $20 \%$. It should be pointed out that the effects of salts and $\mathrm{ACN}-\mathrm{H}_{2} \mathrm{O}$ mixture on $\mathrm{BPB}$ (Figure S1 in Supplementary Materials) were similar to those on BPA. Based on the above results, $0.3 \mathrm{~g}$ of $\mathrm{NaCl}$ and $\mathrm{ACN}-\mathrm{H}_{2} \mathrm{O}$ mixture with concentration of 4:6 $(v / v)$ were selected as the optimal salting-out conditions, as they provided the highest signal response.

\subsection{Clean-Up Performance}

In this $\mu$-SOA-MSPD method, sorbent could be introduced into the blending step to improve clean-up performance. Bisphenol analytes were separated in reversed-phase HPLC and detected by fluorescence detector (FLD) (Figure 3). To better illustrate the cleanup effect, UV-Vis signal was recorded by diode array detector (DAD). As shown in Figure 4a, introduction of PSA in the blending exhibited remarkable reduction of matrix peaks. It was noticed that the clean-up behavior was happened in the lower retention time, which implied that relative polar compounds in the matrix might be removed by PSA. This was consistent with the reported results using PSA-based solid-phase extraction, that the PSA pipette column showed an excellent retention of phenolic compounds in bee pollen [37]. Therefore, the HPLC condition for the separation of phenolic compounds [29,38] was implemented to further demonstrate the clean-up ability. As indicated in Figure $4 \mathrm{~b}$, intensive matrix peaks were observed in the chromatogram of extract prepared in the absence of sorbent. Interestingly, these peaks were dramatically reduced with the addition of PSA in the blending. As the mass of PSA increased to $0.4 \mathrm{~g}$, peaks area located from RT $50 \mathrm{~min}$ to 70 min were significantly reduced to only $4 \%$ of that obtained without addition of PSA. These DAD results demonstrated the excellent clean-up ability when the sorbent was added in the blending process. Meanwhile, for the fluorescence detection of bisphenols, the HPLC chromatogram was selective and clear enough, and no additional improvement in FLD was observed when the PSA was introduced (Figure S2). Therefore, in the case of bisphenols determination in bee pollen using HPLC-FLD, $\mu$-SOA-MSPD could be performed by simply blended with salt without the presence of PSA.

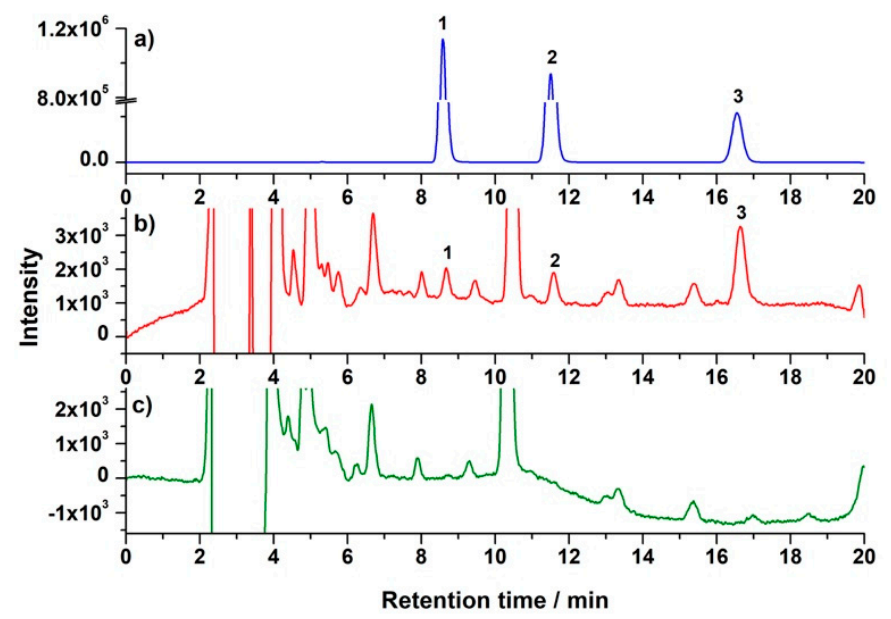

Figure 3. Representative HPLC-fluorescence detector (FLD) chromatograms of (a) bisphenol standards, (b) spiked bee pollen sample, and (c) blank bee pollen sample. Peak 1: bisphenol A (BPA); 2: bisphenol B (BPB); 3: internal standard (IS). The spiked concentrations in (b) were $60 \mu \mathrm{g} / \mathrm{kg}$ and $80 \mu \mathrm{g} / \mathrm{kg}$ for BPA and BPB, respectively. 

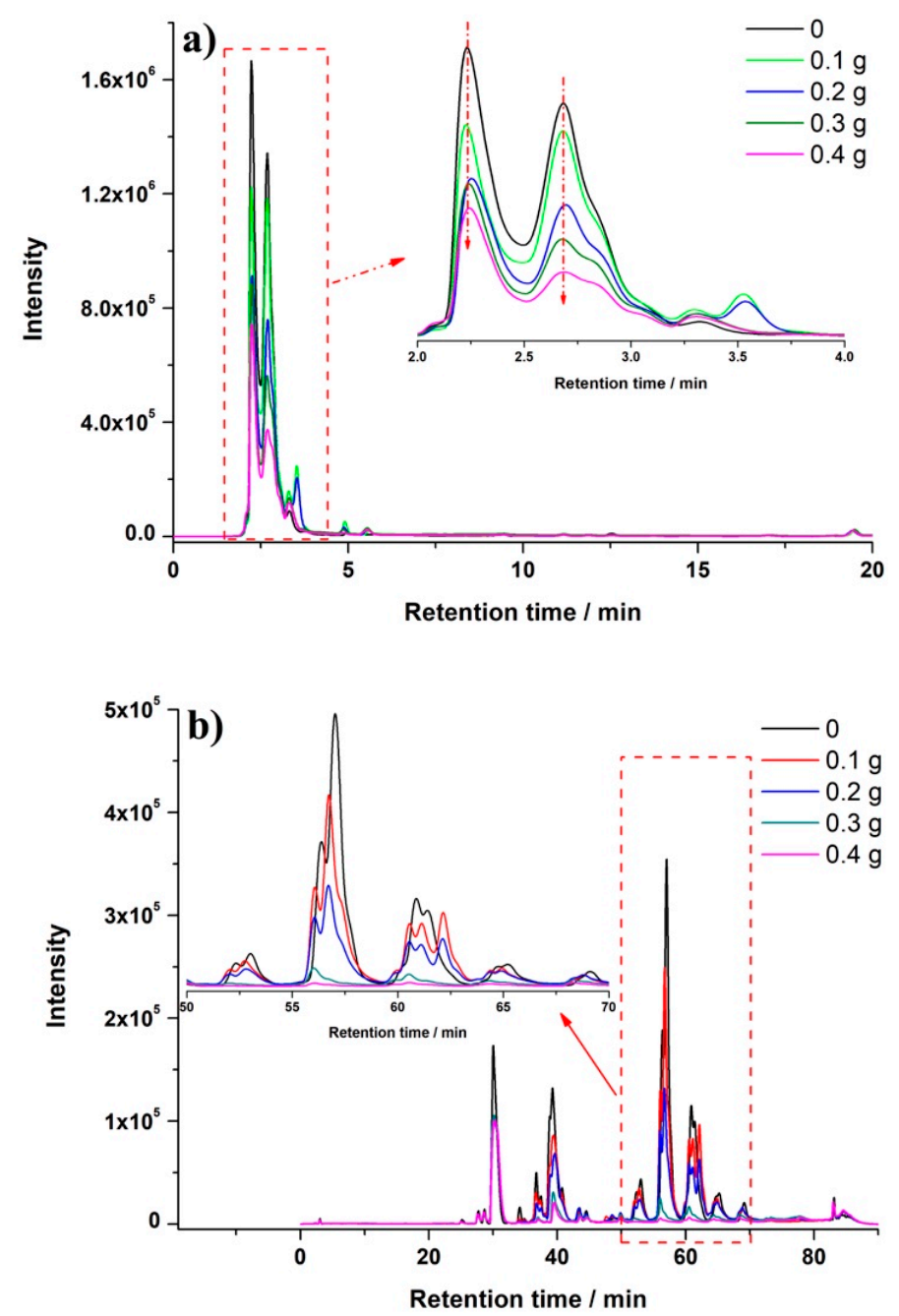

Figure 4. Representative HPLC-DAD chromatograms of extract under different masses of PSA. (a) Separation was performed for the analysis of bisphenols $(\lambda=210 \mathrm{~nm})$, (b) separation was performed for the analysis of phenolic compounds $(\lambda=280 \mathrm{~nm})$.

\subsection{Method Validation}

Seven levels of calibration curves ranging from $0.002 \mu \mathrm{g} / \mathrm{mL}$ to $0.4 \mu \mathrm{g} / \mathrm{mL}$ were applied for the quantification. Good linearity with correlation coefficients of $>0.9995$ were achieved. The limits of detection (LOD, $\mathrm{S} / \mathrm{N}=3$ ) for BPA and BPB in bee pollen sample were $20 \mu \mathrm{g} / \mathrm{kg}$ and $30 \mu \mathrm{g} / \mathrm{kg}$, respectively; and the limits of quantification (LOQ, S/N =10) were $60 \mu \mathrm{g} / \mathrm{kg}$ and $80 \mu \mathrm{g} / \mathrm{kg}$, respectively. With spiked level of LOQ, concentration of analytes in the final extractant was about $0.008 \mu \mathrm{g} / \mathrm{mL}$. The accuracy and precision were investigated in blank bee pollen sample spiked at three levels $(1 \times \mathrm{LOQ}, 5 \times \mathrm{LOQ}$, and $10 \times$ LOQ). Results of the calculated recoveries and RSDs are shown in Table 1 . The average recoveries for BPA and BPB were between $87.70 \%$ and $94.64 \%$, and between $83.03 \%$ and $89.59 \%$, respectively. The precisions were in the range of $1.76 \%$ to $5.21 \%$, and $2.07 \%$ to $5.45 \%$ for $\mathrm{BPA}$ and $\mathrm{BPB}$, respectively. All the results were in the acceptable range according to the AOAC [39]. In addition, eleven commercial rape bee pollen samples collected from local markets were analyzed using the proposed method. The results showed that no bisphenols were detected in these samples. More samples using different species of bee pollen should be investigated to reveal the contamination level of bisphenols. In addition, improving the enriching effect of the sample preparation method would be helpful for detecting ultra-low level of bisphenols in bee pollen. We observed lower volumes of extractant phase when a lower mass of salts and lower concentration of $\mathrm{ACN}$ in the $\mathrm{ACN}-\mathrm{H}_{2} \mathrm{O}$ mixture were used in 
the $\mu$-SOA-MSPD. This would be valuable for the further development of micro-extraction methodology. These studies are under way.

Table 1. Accuracy and precision of the proposed method at three spiked levels.

\begin{tabular}{|c|c|c|c|c|c|c|c|c|c|}
\hline \multirow[b]{3}{*}{ Analytes } & \multirow{3}{*}{$\begin{array}{l}\text { Spiked Levels } \\
\quad(\mu \mathrm{g} / \mathrm{kg})\end{array}$} & \multicolumn{6}{|c|}{ Intra-Day } & \multirow{2}{*}{\multicolumn{2}{|c|}{ Inter-Day }} \\
\hline & & \multicolumn{2}{|c|}{ Day 1} & \multicolumn{2}{|c|}{ Day 2} & \multicolumn{2}{|c|}{ Day 3} & & \\
\hline & & $\begin{array}{c}\begin{array}{c}\text { Recovery } \\
(\mathrm{Mean} \pm \mathrm{SD} \\
\%, n=6)\end{array}\end{array}$ & $\begin{array}{c}\mathrm{RSD} \\
(\%, n=6)\end{array}$ & $\begin{array}{c}\begin{array}{c}\text { Recovery } \\
(\text { Mean } \pm \text { SD, } \\
\%, n=6)\end{array}\end{array}$ & $\begin{array}{c}\text { RSD } \\
(\%, n=6)\end{array}$ & $\begin{array}{c}\text { Recovery } \\
\text { (Mean } \pm \mathrm{SD}, \\
\%, n=6)\end{array}$ & $\begin{array}{c}\text { RSD } \\
(\%, n=6)\end{array}$ & $\begin{array}{c}\text { Recovery } \\
(\text { Mean } \pm \text { SD } \\
\%, n=18)\end{array}$ & $\begin{array}{c}\text { RSD } \\
(\%, n=18)\end{array}$ \\
\hline \multirow{3}{*}{ BPA } & 60 & $92.70 \pm 4.13$ & 4.46 & $90.19 \pm 4.41$ & 4.89 & $94.64 \pm 3.59$ & 3.79 & $92.51 \pm 4.24$ & 4.59 \\
\hline & 300 & $89.13 \pm 1.57$ & 1.76 & $88.44 \pm 2.75$ & 3.11 & $87.70 \pm 4.57$ & 5.21 & $88.43 \pm 3.07$ & 3.47 \\
\hline & 600 & $89.04 \pm 3.08$ & 3.46 & $90.16 \pm 2.92$ & 3.24 & $88.30 \pm 2.25$ & 2.55 & $89.16 \pm 2.81$ & 3.15 \\
\hline \multirow{3}{*}{$\mathrm{BPB}$} & 80 & $85.14 \pm 2.31$ & 2.71 & $89.59 \pm 4.46$ & 4.98 & $85.25 \pm 4.65$ & 5.45 & $86.66 \pm 4.28$ & 4.94 \\
\hline & 400 & $84.29 \pm 2.26$ & 2.68 & $83.18 \pm 2.20$ & 2.64 & $83.46 \pm 2.50$ & 3.00 & $83.64 \pm 2.24$ & 2.68 \\
\hline & 800 & $83.03 \pm 1.72$ & 2.07 & $83.26 \pm 1.69$ & 2.03 & $83.68 \pm 2.61$ & 3.12 & $83.32 \pm 1.99$ & 2.39 \\
\hline
\end{tabular}

\section{Materials and Methods}

\subsection{Materials}

ACN (HPLC grade) was obtained from Merck (Darmstadt, Germany). Standards of BPA, BPB, and 4, 4'-cyclohexylidenebisphenol (internal standard, IS) were purchased from Aladdin (Shanghai, China). $\mathrm{MgSO}_{4}$ was from Sinopharm Chemical Reagent $\mathrm{Co}$., Ltd. (Shanghai, China) and $\mathrm{NaCl}$ was from Xilong Science Co., Ltd. (Guangdong, China). The PSA was obtained from Sepax (Suzhou, China). Ultrapure water (18.2 M $\Omega$ ) was used through this article. Rape (Brassica campestris) bee pollen used for the method development was collected in Hubei, China. Commercial rape bee pollen samples applied in the method application were purchased from local markets. Stock solution of standards were prepared in $\mathrm{ACN}$ at the concentration of $1 \mathrm{mg} / \mathrm{mL}$. Working standard solutions were prepared by further diluted with ACN. All standard solutions were stored at $4{ }^{\circ} \mathrm{C}$ until used.

\subsection{Optimal Micro Salting-Out Assisted MSPD}

A bee pollen sample $(0.1 \mathrm{~g})$ and $\mathrm{NaCl}(0.3 \mathrm{~g})$ were blended together for $30 \mathrm{~s}$, and then the materials were transferred into a $10 \mathrm{~mL}$ tube. After the addition of $4 \mathrm{~mL}$ of $\mathrm{ACN}-\mathrm{H}_{2} \mathrm{O}$ $(4: 6, v / v)$ solution, the mixture was vortexed for $1 \mathrm{~min}$. Then the mixed solution was centrifuged at $6000 \mathrm{rpm}$ for $5 \mathrm{~min}$ to make the phase separation clear. Aliquot of the upper phase was collected and analyzed by HPLC.

\subsection{Optimization of Salting-Out Parameters}

A bee pollen sample $(0.1 \mathrm{~g})$ was spiked with $10 \mu \mathrm{L}$ of standards solution $(100 \mu \mathrm{g} / \mathrm{mL}$ of BPA and BPB) and $10 \mu \mathrm{L}$ of IS solution $(100 \mu \mathrm{g} / \mathrm{mL})$, then stood for $30 \mathrm{~min}$. The spiked sample with different masses of salts $\left(\mathrm{MgSO}_{4}\right.$ and $\mathrm{NaCl}$ with total amount from $0.3 \mathrm{~g}$ to $0.5 \mathrm{~g}$ ) were blended together, then the materials were transferred into a $10 \mathrm{~mL}$ tube. After the addition of $4 \mathrm{~mL}$ of different $\mathrm{ACN}-\mathrm{H}_{2} \mathrm{O}$ solutions $(4: 6,5: 5,6: 4$, and $7: 3, v / v)$, the mixture was vortexed for $1 \mathrm{~min}$. Then the mixed solution was centrifuged at $6000 \mathrm{rpm}$ for $5 \mathrm{~min}$, and an aliquot of the upper phase was collected and analyzed by HPLC.

\subsection{Clean-Up Effect of PSA in the Micro Salting-Out Assisted MSPD}

The spiked bee pollen sample with different masses of PSA $(0.1,0.2,0.3$, and $0.4 \mathrm{~g})$ and $0.3 \mathrm{~g}$ of $\mathrm{NaCl}$ were blended together, then the materials were transferred into a $10 \mathrm{~mL}$ tube. After the addition of $4 \mathrm{~mL}$ of $\mathrm{ACN}-\mathrm{H}_{2} \mathrm{O}$ solution $(4: 6, \mathrm{v} / \mathrm{v})$, the mixture was vortexed for $1 \mathrm{~min}$. Then the mixed solution was centrifuged at $6000 \mathrm{rpm}$ for $5 \mathrm{~min}$, and an aliquot of the upper phase was collected and analyzed by HPLC.

\subsection{HPLC Analysis}

The HPLC system consisted of LC-20AT pump, SIL-20AC autosampler, CTO-20AC column oven, SPD-M20A DAD and RF20-AXL FLD. 
For the analysis of bisphenols, an InertSustain (Shimadzu GL, Tokyo, Japan) C18 column $(4.6 \mathrm{~mm} \times 250 \mathrm{~mm}, 5 \mu \mathrm{m})$ was used for the separation. The mobile phase consisted of water (solvent A) and ACN (solvent B). Chromatographic conditions were carried out as follows: $47 \%$ solvent $\mathrm{B}$ at $0-14 \mathrm{~min}, 47 \%$ to $80 \%$ at $14-17 \mathrm{~min}$, and maintained at $80 \%$ at 17-20 $\mathrm{min}$, then post-run with $3 \mathrm{~min}$ for back to $47 \%$ and maintained at $47 \%$ for $10 \mathrm{~min}$. The flow rate was $1 \mathrm{~mL} / \mathrm{min}$, injection volume was $10 \mu \mathrm{L}$, and the column temperature was $35{ }^{\circ} \mathrm{C}$. The detection wavelength of DAD was $210 \mathrm{~nm}$, and the excitation and emission wavelength of FLD were $270 \mathrm{~nm}$ and $305 \mathrm{~nm}$, respectively.

Phenolic compounds were separated based on the previously reported method [29,38]. A WondaCract ODS-2 (Shimadzu GL, Tokyo, Japan) C18 column $(4.6 \mathrm{~mm} \times 150 \mathrm{~mm}, 5 \mu \mathrm{m})$ was applied for the separation. The mobile phase consisted of water with $0.1 \%(v / v)$ acetic acid (solvent A) and methanol (solvent B). Chromatographic conditions were carried as follows: $15-40 \%$ solvent B at $0-30 \mathrm{~min}, 40-55 \%$ at $30-65 \mathrm{~min}, 55-62 \%$ at $65-70 \mathrm{~min}, 62-100 \%$ at $70-80 \mathrm{~min}$, then back to $15 \%$ at $80-85 \mathrm{~min}$ and maintained at $15 \%$ for $5 \mathrm{~min}$. The flow rate was $0.8 \mathrm{~mL} / \mathrm{min}$, injection volume was $10 \mu \mathrm{L}$, and the column temperature was $35^{\circ} \mathrm{C}$. The detection wavelength of DAD was $280 \mathrm{~nm}$.

\subsection{Method Validation}

Seven-level standard curves were prepared containing BPA $(0.002,0.01,0.02,0.05$, $0.1,0.2$, and $0.4 \mu \mathrm{g} / \mathrm{mL}), \mathrm{BPB}(0.002,0.01,0.02,0.05,0.1,0.2$, and $0.4 \mu \mathrm{g} / \mathrm{mL})$, and IS $(0.1 \mu \mathrm{g} / \mathrm{mL})$. The ratio of peak area (analyte/IS) versus the ratio of weight (analyte/IS) was used to construct the analytical curves. The y-intercept was set to zero and a linear fit was performed. Blank bee pollen sample with the absence of analytes was used for the method validation. The limit of detection (LOD) and limit of quantification (LOQ), defined as $3 \times \mathrm{S} / \mathrm{N}$ (signal/noise) and $10 \times \mathrm{S} / \mathrm{N}$, respectively, were investigated in spiked blank bee pollen samples, which were prepared as described in Section 3.2. Accuracy and precision studies were estimated by analyzing blank samples spiked at three levels $(1 \times \mathrm{LOQ}, 5 \times \mathrm{LOQ}$, and $10 \times \mathrm{LOQ}$ ), which were prepared as described in Section 3.2. Recovery was used to express the accuracy, and the precision was determined as relative standard deviation $(\mathrm{RSD})$ to the mean recovery in repeatability (intra-day, $n=6$ ) and intermediate precision (inter-day, three consecutive days, $n=18$ ) analysis.

\section{Conclusions}

In summary, a new sample preparation method, $\mu$-SOA-MSPD, was developed for the analysis of bisphenol contaminants in bee pollen. Salt and the $\mathrm{ACN}-\mathrm{H}_{2} \mathrm{O}$ mixture could be designed to achieve better recovery and signal response. In addition, the introduction of sorbent in the blending step showed excellent removal of matrix components. The proposed method was fully validated, and the results indicated that it was suitable for the reliable and sensitive detection of BPA and BPB residues in spiked bee pollen. The proposed method was simple, rapid, and provided advantages in saving time, labor, and solvents. Since the flexibility of MSPD technology in different matrices, this modified MSPD method would be valuable for the fast sample preparation of other solid and semi-solid samples.

Supplementary Materials: The following are available online, Figure S1: Effects of salts and ACN$\mathrm{H}_{2} \mathrm{O}$ mixture on the calculated recovery and signal response of BPB. Figure S2: Representative HPLC-FLD chromatograms of extract under different mass of PSA.

Author Contributions: Conceptualization, W.C. and X.T.; Data curation, J.Z. and F.Y.; Funding acquisition, W.C. and X.T.; Investigation, J.Z. and F.Y.; Methodology, J.Z., W.C. and X.T.; Project administration, X.T.; Resources, W.C. and X.T.; Supervision, W.C. and X.T.; Validation, Y.T. and C.D.; Writing — original draft, W.C. and X.T.; Writing - review \& editing, W.Y., W.C. and X.T. All authors have read and agreed to the published version of the manuscript.

Funding: This research was funded by Natural Science Foundation of Fujian Province, grant number 2020J01535 and 2019J01409, and Natural Science Foundation of China, grant number 32072799.

Institutional Review Board Statement: Not applicable. 
Informed Consent Statement: Not applicable.

Data Availability Statement: The data presented in this study are available on request from the corresponding author.

Conflicts of Interest: The authors declare no conflict of interest.

Sample Availability: Samples of the compounds are not available from the authors.

\section{References}

1. Capriotti, A.L.; Cavaliere, C.; Giansanti, P.; Gubbiotti, R.; Samperi, R.; Lagana, A. Recent developments in matrix solid-phase dispersion extraction. J. Chromatogr. A 2010, 1217, 2521-2532. [CrossRef]

2. Capriotti, A.L.; Cavaliere, C.; Foglia, P.; Samperi, R.; Stampachiacchiere, S.; Ventura, S.; Laganà, A. Recent advances and developments in matrix solid-phase dispersion. Trends Anal. Chem. 2015, 71, 186-193. [CrossRef]

3. Tu, X.; Chen, W. A Review on the Recent Progress in Matrix Solid Phase Dispersion. Molecules 2018, 23, 2767. [CrossRef]

4. Ramos, L. Use of new tailored and engineered materials for matrix solid-phase dispersion. Trends Anal. Chem. 2019, 118, 751-758. [CrossRef]

5. Barker, S.A. Matrix solid-phase dispersion. J. Chromatogr. A 2000, 885, 115-127. [CrossRef]

6. Barker, S.A. Matrix solid phase dispersion (MSPD). J. Biochem. Biophys. Methods 2007, 70, 151-162. [CrossRef]

7. Ramos, J.J.; Rial-Otero, R.; Ramos, L. Ultrasonic-assisted matrix solid-phase dispersion as an improved methodology for the determination of pesticides in fruits. J. Chromatogr. A 2008, 1212, 145-149. [CrossRef] [PubMed]

8. Aznar, R.; Albero, B.; Perez, R.A.; Sanchez-Brunete, C.; Miguel, E.; Tadeo, J.L. Analysis of emerging organic contaminants in poultry manure by gas chromatography-tandem mass spectrometry. J. Sep. Sci. 2018, 41, 940-947. [CrossRef] [PubMed]

9. Hertzog, G.I.; Soares, K.L.; Caldas, S.S.; Primel, E.G. Study of vortex-assisted MSPD and LC-MS/MS using alternative solid supports for pharmaceutical extraction from marketed fish. Anal. Bioanal. Chem. 2015, 407, 4793-4803. [CrossRef] [PubMed]

10. León-González, M.E.; Rosales-Conrado, N. Determination of ibuprofen enantiomers in breast milk using vortex-assisted matrix solid-phase dispersion and direct chiral liquid chromatography. J. Chromatogr. A 2017, 1514, 88-94. [CrossRef] [PubMed]

11. Chen, S.J.; Du, K.Z.; Li, J.; Chang, Y.X. A chitosan solution-based vortex-forced matrix solid phase dispersion method for the extraction and determination of four bioactive constituents from Ligustri Lucidi Fructus by high performance liquid chromatography. J. Chromatogr. A 2020, 1609, 460509. [CrossRef]

12. Chung, W.H.; Lin, J.S.; Ding, W.H. Dual-vortex-assisted matrix solid-phase dispersion coupled with isotope-dilution ultrahighperformance liquid chromatography-high resolution mass spectrometry for the rapid determination of parabens in indoor dust samples. J. Chromatogr. A 2019, 1605, 460367. [CrossRef]

13. Gomez-Mejia, E.; Rosales-Conrado, N.; Leon-Gonzalez, M.E.; Madrid, Y. Determination of phenolic compounds in residual brewing yeast using matrix solid-phase dispersion extraction assisted by titanium dioxide nanoparticles. J. Chromatogr. A 2019, 1601, 255-265. [CrossRef]

14. Kemmerich, M.; Demarco, M.; Bernardi, G.; Prestes, O.D.; Adaime, M.B.; Zanella, R. Balls-in-tube matrix solid phase dispersion (BiT-MSPD): An innovative and simplified technique for multiresidue determination of pesticides in fruit samples. J. Chromatogr. A 2020, 1612, 460640. [CrossRef] [PubMed]

15. Chatzimitakos, T.G.; Anderson, J.L.; Stalikas, C.D. Matrix solid-phase dispersion based on magnetic ionic liquids: An alternative sample preparation approach for the extraction of pesticides from vegetables. J. Chromatogr. A 2018, 1581-1582, 168-172. [CrossRef] [PubMed]

16. Fotouhi, M.; Seidi, S.; Shanehsaz, M.; Naseri, M.T. Magnetically assisted matrix solid phase dispersion for extraction of parabens from breast milks. J. Chromatogr. A 2017, 1504, 17-26. [CrossRef]

17. Guerra, E.; Celeiro, M.; Lamas, J.P.; Llompart, M.; Garcia-Jares, C. Determination of dyes in cosmetic products by micro-matrix solid phase dispersion and liquid chromatography coupled to tandem mass spectrometry. J. Chromatogr. A 2015, 1415, 27-37. [CrossRef] [PubMed]

18. Chen, Q.; Lin, Y.; Tian, Y.; Wu, L.; Yang, L.; Hou, X.; Zheng, C. Single-Drop Solution Electrode Discharge-Induced Cold Vapor Generation Coupling to Matrix Solid-Phase Dispersion: A Robust Approach for Sensitive Quantification of Total Mercury Distribution in Fish. Anal. Chem. 2017, 89, 2093-2100. [CrossRef]

19. Deng, T.; Wu, D.; Duan, C.; Yan, X.; Du, Y.; Zou, J.; Guan, Y. Spatial Profiling of Gibberellins in a Single Leaf Based on Microscale Matrix Solid-Phase Dispersion and Precolumn Derivatization Coupled with Ultraperformance Liquid Chromatography-Tandem Mass Spectrometry. Anal. Chem. 2017, 89, 9537-9543. [CrossRef] [PubMed]

20. Xu, J.J.; Yang, R.; Ye, L.H.; Cao, J.; Cao, W.; Hu, S.S.; Peng, L.Q. Application of ionic liquids for elution of bioactive flavonoid glycosides from lime fruit by miniaturized matrix solid-phase dispersion. Food Chem. 2016, 204, 167-175. [CrossRef] [PubMed]

21. Xu, J.J.; Cao, J.; Peng, L.Q.; Cao, W.; Zhu, Q.Y.; Zhang, Q.Y. Characterization and determination of isomers in plants using trace matrix solid phase dispersion via ultrahigh performance liquid chromatography coupled with an ultraviolet detector and quadrupole time-of-flight tandem mass spectrometry. J. Chromatogr. A 2016, 1436, 64-72. [CrossRef] [PubMed]

22. Cao, J.; Peng, L.Q.; Xu, J.J.; Du, L.J.; Zhang, Q.D. Simultaneous microextraction of inorganic iodine and iodinated amino acids by miniaturized matrix solid-phase dispersion with molecular sieves and ionic liquids. J. Chromatogr. A 2016, 1477, 1-10. [CrossRef] [PubMed] 
23. Guerra, E.; Llompart, M.; Garcia-Jares, C. Miniaturized matrix solid-phase dispersion followed by liquid chromatographytandem mass spectrometry for the quantification of synthetic dyes in cosmetics and foodstuffs used or consumed by children. $J$. Chromatogr. A 2017, 1529, 29-38. [CrossRef]

24. Chu, C.; Jiang, L.; Mao, H.; Yan, J. A simple and environmentally-friendly method by pipette-tip matrix solid-phase dispersion microextraction coupled with high-performance liquid chromatography for the simultaneous determination of lignans and terpenes. Sustain. Chem. Pharm. 2021, 20, 100384. [CrossRef]

25. Pena-Abaurrea, M.; Ramos, L. Miniaturization of analytical methods. In Challenges in Green Analytical Chemistry, 1st ed.; de la Guardia, M., Garrigues, S., Eds.; Royal Society of Chemistry: Cambridge, UK, 2011; pp. 107-143.

26. Anthemidis, A.N.; Ioannou, K.-I.G. Recent developments in homogeneous and dispersive liquid-liquid extraction for inorganic elements determination. A review. Talanta 2009, 80,413-421. [CrossRef]

27. Dmitrienko, S.G.; Apyari, V.V.; Gorbunova, M.V.; Tolmacheva, V.V.; Zolotov, Y.A. Homogeneous Liquid-Liquid Microextraction of Organic Compounds. J. Anal. Chem. 2020, 75, 1371-1383. [CrossRef]

28. Valente, I.M.; Rodrigues, J.A. Recent advances in salt-assisted LLE for analyzing biological samples. Bioanalysis 2015, 7, $2187-2193$. [CrossRef] [PubMed]

29. Chen, W.; Tu, X.; Wu, D.; Gao, Z.; Wu, S.; Huang, S. Comparison of the Partition Efficiencies of Multiple Phenolic Compounds Contained in Propolis in Different Modes of Acetonitrile-Water-Based Homogenous Liquid-Liquid Extraction. Molecules 2019, 24, 442. [CrossRef]

30. Anastassiades, M.; Lehotay, S.J.; Stajnbaher, D.; Schenck, F.J. Fast and Easy Multiresidue Method Employing Acetonitrile Extraction/Partitioning and "Dispersive Solid-Phase Extraction" for the Determination of Pesticide Residues in Produce. J. AOAC Int. 2003, 86, 412-431. [CrossRef] [PubMed]

31. González-Curbelo, M.Á.; Socas-Rodríguez, B.; Herrera-Herrera, A.V.; González-Sálamo, J.; Hernández-Borges, J.; RodríguezDelgado, M.Á. Evolution and applications of the QuEChERS method. Trends Anal. Chem. 2015, 71, 169-185. [CrossRef]

32. Tu, X.; Wu, S.; Liu, W.; Gao, Z.; Huang, S.; Chen, W. Sugaring-Out Assisted Liquid-Liquid Extraction Combined with HighPerformance Liquid Chromatography-Fluorescence Detection for the Determination of Bisphenol A and Bisphenol B in Royal Jelly. Food Anal. Methods 2019, 12, 705-711. [CrossRef]

33. Inoue, K.; Murayama, S.; Takeba, K.; Yoshimura, Y.; Nakazawa, H. Contamination of xenoestrogens bisphenol A and F in honey: Safety assessment and analytical method of these compounds in honey. J. Food Compos. Anal. 2003, 16, 497-506. [CrossRef]

34. Gałuszka, A.; Konieczka, P.; Migaszewski, Z.M.; Namiesnik, J. Analytical Eco-Scale for assessing the greenness of analytical procedures. Trends Anal. Chem. 2012, 37, 61-72. [CrossRef]

35. Valente, I.M.; Goncalves, L.M.; Rodrigues, J.A. Another glimpse over the salting-out assisted liquid-liquid extraction in acetonitrile/water mixtures. J. Chromatogr. A 2013, 1308, 58-62. [CrossRef] [PubMed]

36. Tu, X.; Sun, F.; Wu, S.; Liu, W.; Gao, Z.; Huang, S.; Chen, W. Comparison of salting-out and sugaring-out liquid-liquid extraction methods for the partition of 10-hydroxy-2-decenoic acid in royal jelly and their co-extracted protein content. J. Chromatogr. B 2018, 1073, 90-95. [CrossRef]

37. Tu, X.; Chen, W. Miniaturized Salting-Out Assisted Liquid-Liquid Extraction Combined with Disposable Pipette Extraction for Fast Sample Preparation of Neonicotinoid Pesticides in Bee Pollen. Molecules 2020, 25, 5703. [CrossRef]

38. Zhang, C.P.; Huang, S.; Wei, W.T.; Ping, S.; Shen, X.G.; Li, Y.J.; Hu, F.L. Development of high-performance liquid chromatographic for quality and authenticity control of Chinese propolis. J. Food Sci. 2014, 79, C1315-C1322.

39. Taverniers, I.; De Loose, M.; Van Bockstaele, E. Trends in quality in the analytical laboratory. II. Analytical method validation and quality assurance. Trends Anal. Chem. 2004, 23, 535-552. [CrossRef] 